\title{
Bandello F, Singh AD, Pelayes DE, Seregard S, Macklis R: Ophthalmic Radiation Therapy Techniques and Applications. Developments in Ophthalmology: Vol. 52
}

\author{
KARGER, 2013, (ISBN: 978-3-318-02440-1)
}

\author{
R. J. W. de Keizer
}

Received: 25 June 2014 / Accepted: 30 June 2014 / Published online: 31 August 2014

(C) Springer-Verlag Berlin Heidelberg 2014

This book is an important asset to the medical literature in the combined fields of radiation and ophthalmology. Ocular oncologists, radiation oncologists, and vitreo-retinal surgeons wrote this book, which has ten chapters. Every chapter is written by separate authorities in their field from the USA and Europe. The book covers basic and advanced radiation therapy techniques, together with specific indications by tumour location in and around the eyeball.

All 15 contributing authors are listed in the contents. One of the founders of ophthalmic radiation, Peter Lommatzsch, wrote the preface. The first chapters introduce the history of the irradiation, technological advances as teletherapy techniques, and tissue tolerances. The next chapters describe the diagnostic and management procedures of the different ocular tumours and other indications such as benign lesions (macular degeneration and haemangiomas). In the last two chapters, the management of complications due to radiation therapy is described in detail for lesions in the face, orbit, sinus, skull area, the anterior and the posterior eye. The authors describe the pros and cons in relation to other treatment policies.

Different types of plaques and treatment modalities of brachytherapy are developed in Europe and in the USA. The techniques are highlighted and the current practices are shown, together with the comprehensive treatment planning.

\footnotetext{
R. J. W. de Keizer $(\bowtie)$

Department of Ophthalmology, UZA and University Antwerp, Antwerp, Belgium

e-mail: robert.de.keizer@uza.be

R. J. W. Keizer

e-mail: r.j.w.de_keizer@lumc.nl

R. J. W. de Keizer

Em of Leiden University Medical Center, P O Box: 9600, 2300

RC Leiden, Netherlands
}

This chapter brachytherapy also shows nicely how well and adequately the book is illustrated.

In the chapter covering retinal tumours, the most common paediatric tumours are presented. The recently proposed "classification system for intraocular retinoblastoma" is also added. Attention is paid to radiation-induced secondary tumours.

A relatively new field in treatment of neo-vascular agerelated macular degeneration (NVAMD) is radiation therapy. The past, present, and future of radiation as a sole treatment or combination with anti VEGF therapy is discussed. As the book is not only meant for the ophthalmologist, AMD is explained in detail for the radiotherapist.

The contributors succeeded in writing an educating textbook and review, which is easily readable. The text is completed with good-quality illustrations, photographs, and flow diagrams. The descriptions are important for every general and academic working ophthalmologist encountering ocular tumours and irradiated patients. The basic principles of radiotherapy are outlined in an educative manner, showing the differences between isotopes, particle radiation, and so on. All topics are discussed deeply and in detail, with a lot of references. The management of eyelid and conjunctival tumours is adequate - however, less extensively than the other chapters.

Although we live in the "cloud" and we get information easily and directly from the internet, this book is an important reference for all who work in the field of ophthalmology and radiotherapy. It is not only meant for the super specialists but also for the co-working nurses, labtechnicians, residents, fellows, and others. In my opinion, this book deserves a place in every library of these departments.

In summary: this book, in hardcover, can be highly recommended to every ophthalmologist and radiotherapist, it should have a place in his or her library. It is a practical guide to understanding the relationships between radiation and the eye, its indications and complications. 